\title{
Hospitalização em Oncologia Pediátrica e Desenvolvimento Infantil: Interfaces entre Aspectos Cognitivos e Afetivos
}

\author{
Luiza Garutti Alvarenga Fonseca ${ }^{1}$ \\ ${ }^{1}$ Universidade Federal de São Paulo, SP, Brasil. \\ Sara Del Prete Panciera ${ }^{1}$ \\ ${ }^{1}$ Universidade Federal de São Paulo, SP, Brasil. \\ Karina Franco Zihlmann ${ }^{1}$ \\ ${ }^{1}$ Universidade Federal de São Paulo, SP, Brasil.
}

Resumo: O diagnóstico e o tratamento de câncer na infância exigem que a criança construa formas de enfrentamento, o que torna relevante compreender sua percepção e o modo como se organiza cognitivamente. O objetivo deste estudo foi caracterizar de que maneira os processos de hospitalização e tratamento são compreendidos pelos participantes diante da vivência de neoplasia infantil, considerando a etapa de desenvolvimento cognitivo e afetivo, de acordo com a perspectiva piagetiana. Foi realizada uma pesquisa qualitativa no ambulatório de oncologia pediátrica em um hospital da Baixada Santista, com entrevistas semiestruturadas, provas piagetianas e desenhos-estórias com tema, com uma amostra de conveniência de cinco crianças com entre 4 e 9 anos e com diagnóstico de leucemia. Os dados foram categorizados pela análise de conteúdo temática de Bardin (1988), as provas piagetianas de acordo com a teoria de Piaget e os desenhos-estórias a partir de Trinca (2002). Duas crianças (com 4 e 6 anos) se caracterizaram como pré-operatórias e três (com 8 e 9 anos) como operatórias concretas, sendo observado que as pré-operatórias apresentam um discurso com alta carga simbólica sobre o sofrimento da hospitalização e tratamento, enquanto crianças operatório-concretas demonstram domínio da noção de causa e consequência e pensamento lógico. Uma comparação qualitativa entre as provas piagetianas e os desenhos indicou coerência entre os tipos de avaliação. Todos os participantes mostram compreensão de sua atual situação de adoecimento e tratamento, apresentando diferentes formas de enfrentamento. Além disso, todos ressaltaram uma posição otimista em relação às perspectivas de cura, independentemente do momento do desenvolvimento cognitivo.

Palavras-chave: Oncologia pediátrica, Teoria piagetiana do desenvolvimento cognitivo, Hospitalização, Procedimento desenho e estória com tema.

\section{Hospitalization in Pediatric Oncology and Child Development: Cognitive and Affective Interface}

\begin{abstract}
Diagnosing and treating childhood cancer requires children to develop coping strategies, indicating the need for understanding their perception and cognitive organization. Thus, this study aimed to understand how participants perceive the process of hospitalization and treatment for childhood neoplasia according to Piaget's stages of cognitive and affective development. This is a qualitative study conducted with a convenience sample of five children aged between 4 and 9 years, diagnosed with Leukemia and treated at a pediatric oncology outpatient clinic in a hospital in Baixada Santista, São Paulo, Brazil. Data were collected using semi-structured interviews, Piagetian proofs, and thematic drawing-and-story procedure and analyzed in the light of Bardin's Thematic Content Analysis (1988), Piaget's theory, and Trinca's theory (2002), respectively. Two children (4 and 6 years old) were characterized as preoperative and three ( 8 and 9 years old) as concrete operative. The discourse of preoperative children included high levels of symbolism
\end{abstract}


regarding the suffering arising from hospitalization and the effects of treatment, while concreteoperative children demonstrated mastery of the notion of cause and consequence and logical thinking. A qualitative comparison between Piagetian Proofs and drawings showed consistency between the types of evaluation. All participants show an understanding of their current condition and treatment, presenting different forms of coping. They also highlighted an optimistic position regarding the prospects for healing, regardless of their cognitive development stage.

Keywords: Pediatric oncology, Piagetian theory of cognitive development, Hospitalization, Thematic drawing-and-story procedure.

\title{
Hospitalización en Oncología Pediátrica y Desarrollo Infantil: Interfaces entre Aspectos Cognitivos y Afectivos
}

\begin{abstract}
Resumen: El diagnóstico y tratamiento de cáncer infantil requiere del niño la construcción de formas de enfrentamiento de la enfermedad, lo que hace relevante la necesidad de comprender su percepción y el modo cómo se organiza cognitivamente. Este estudio tuvo como objetivo caracterizar de qué manera el proceso de hospitalización y tratamiento por neoplasia infantil son comprendidos por los participantes, considerando su etapa de desarrollo cognitivo según la perspectiva piagetiana. Se realizó una investigación cualitativa en el ambulatorio de oncología pediátrica en un hospital de la Baixada Santista (Brasil), con entrevistas semiestructuradas, pruebas piagetianas y dibujoshistorias con tema, con una muestra de cinco niños de entre 4 y 9 años de edad y con diagnóstico de leucemia. Los datos fueron categorizados por el análisis de contenido temático de Bardin (1988), las pruebas piagetianas de acuerdo con la teoría de Piaget y los dibujos-historias mediante Trinca (2002). Dos niños (con 4 y 6 años) se caracterizaron en la etapa preoperacional, y tres (con 8 y 9 años) en la de operaciones concretas, siendo observado que los niños en la etapa preoperacional presentan un discurso con alta carga simbólica sobre el sufrimiento de la hospitalización y tratamiento, mientras que niños en la de operaciones concretas tienen dominio de la noción de causa y consecuencia y pensamiento lógico. Una comparación cualitativa entre las pruebas piagetianas y los dibujos mostró coherencia entre los tipos de evaluación. Todos los participantes comprendían su actual situación de enfermedad y tratamiento, presentando diferentes formas de enfrentamiento. Además, todos resaltaron una actitud optimista en relación a las perspectivas de curación, independiente del momento del desarrollo cognitivo.
\end{abstract}

Palabras clave: Oncología pediátrica, Teoría del desarrollo cognitivo de Piaget, Hospitalización, Estrategia dibujo con tema.

\section{Introdução}

O câncer é a terceira maior causa de morte infantil no Brasil (Anders \& Souza, 2009) e o Instituto Nacional de Câncer (Inca, 2014) estima 11.840 novos casos de neoplasias infantis por ano, sendo o tipo mais recorrente a leucemia. Atualmente, em paralelo ao aumento da incidência, observa-se também um aumento das taxas de cura, embora ainda exista associação com aspectos negativos e estigmatização (Souza \& Erdmann, 2003).

Além do avanço no enfrentamento do câncer infantil do ponto de vista biomédico, há também o desenvolvimento do campo da psico-oncologia pediátrica, com um vasto espectro de investigações (Araújo, 2004). A maior parte dos pesquisadores, entretanto, concorda que há ainda necessidade de mais investigações sobre os fatores psicossociais relacionados ao tratamento do câncer infantil (Menezes, Passareli, Drude, Santos, \& Valle, 2007).

$\mathrm{O}$ diagnóstico de câncer infantil muda completamente a vida da criança e seus familiares, pois ela é subitamente inserida no contexto hospitalar - um ambiente desconhecido -, cercada por pessoas estra- 
nhas e submetida a exames invasivos e dolorosos, como comentam Menezes et al. (2007). Os autores também relatam que, independentemente da idade da criança e de seu nível de compreensão da realidade que a cerca, é frequente que ela seja capaz de perceber que algo grave está acontecendo. Sendo assim, o sofrimento da criança com câncer pode estar ligado não apenas à doença, mas, também, ao distanciamento de sua rotina e ambiente familiar.

A hospitalização em oncologia pediátrica apresenta desafios para a própria equipe de saúde, que busca promover um ambiente no qual as crianças se sintam seguras e no qual suas necessidades físicas e psicossociais sejam atendidas (Utkan, 2012). Bradding e Horstman (1999) ressaltam a importância de que profissionais de saúde estejam sempre à procura de maneiras que permitam que as crianças se expressem quanto a suas necessidades, para que seus pontos de vista sejam levados em consideração quando estão doentes, podendo realizar um trabalho no qual colaboram como facilitadoras durante o tratamento. Entretanto, os autores advertem que isso só se torna possível quando os profissionais e os pais realmente são capazes de levar em conta o ponto de vista da criança.

Ao longo da vida, o ser humano vive processos de adaptação e, ao deparar-se com uma doença, o processo de adoecimento pode ser vivido como uma ruptura em seu cotidiano e em seu modo de existir. A criança, da mesma forma, ao vivenciar o processo de adoecimento, precisa construir formas de enfrentar as repercussões da doença (Anders \& Souza, 2009). Nesse contexto, cabe indagar como ela poderá conceber sua situação de adoecimento, internação e tratamento, a partir de seu momento de desenvolvimento cognitivo específico. Sabe-se que a criança com câncer vive seu processo de desenvolvimento em meio ao contexto do ambiente hospitalar (Utkan, 2012), o que torna ainda mais relevante a necessidade de compreender sua percepção sobre essa situação, levando em conta o modo como ela se organiza cognitivamente.

A perspectiva piagetiana pode contribuir particularmente nesse sentido, na medida em que trata das transformações cognitivas que vão em direção à constituição de uma forma lógico-formal de organização do pensamento (Piaget, 1964). São descritos quatro estágios pelos quais as crianças passariam nessa trajetória: sensório-motor (aproximadamente de 0 a 2 anos), pré-operatório (2 a 7 anos), operatório-concreto ( 7 a 12 anos) e operatório-formal (adolescência).
No primeiro deles, período sensório-motor, a criança não tem ainda a possibilidade de simbolizar, ou seja, de representar internamente os acontecimentos ou objetos externos (Piaget, 1970). Nesse estágio, a criança vai encontrar soluções práticas por meio da ação e do movimento, e sua relação com o mundo será, portanto, pautada pelas ações, sensações e percepções.

Segundo Piaget (1975), a criança pré-operatória se organiza cognitivamente de forma egocêntrica e seria capaz de representar mentalmente o mundo, sem, entretanto, a habilidade de ter outras representações sobre o mundo além da sua própria. Um efeito disso é a criança estender suas ideias, sentimentos e pensamentos para toda a realidade física e social. Na compreensão da criança, portanto, todas as pessoas saberiam, gostariam e pensariam tudo o que ela própria sabe, gosta e pensa, além de conceber coisas e seres não humanos como dotados de alma e intenção, ao que se denomina animismo (Piaget \& Inhelder, 1999). No curso do desenvolvimento, o pensamento egocêntrico vai se tornando pouco a pouco mais socializado, o que leva a criança a se tornar capaz de colocar seu ponto de vista como apenas um no conjunto de pontos de vista, marcando sua passagem para o período operatório-concreto.

O pensamento lógico, característico do período operatório-concreto, permite que se considerem as características dos objetos/informações em trânsito entre o que é geral e o que é particular, possibilitando classificar as informações por meio de operações mentais de categorias (Piaget, 1999). O pensamento egocêntrico da criança pré-operatória, que era transdutivo, não permitia o trânsito entre os aspectos gerais e os particulares.

Outras características do pensamento lógico que não estão presentes, portanto, na organização pré-operatória são a reversibilidade - que implica um percurso do pensamento, partindo de determinado ponto e passando por uma série de transformações para então realizar uma operação análoga e inversa para reencontrar seu ponto de partida não modificado -, e a noção de conservação ou de invariância, que diz respeito à noção de que os objetos têm identidade própria, independentemente das mudanças em sua aparência. Sem essas possibilidades cognitivas, quando se veem em situações em que devem fazer julgamentos sobre transformações físicas, as crianças pré-operatórias irão se basear sempre na sua percepção (Piaget, 1964). 
A noção de causalidade, assim como a de espaço e tempo, é construída ao longo do desenvolvimento, e está relacionada a um jeito lógico de pensar; isso porque, para compreender relações de causa e efeito, é preciso operar relações lógicas, o que não é ainda possível para crianças pré-operatórias, que orientam seus julgamentos com base nas suas percepções (Piaget, 1970).

No último estágio, o período operatório-formal, a grande conquista será a construção da habilidade, extremamente complexa, de operar conceitos abstratos (Piaget \& Inhelder, 1999).

Esses estágios são formas qualitativamente distintas de organização cognitiva e condicionariam formas muito diferentes de compreender e, portanto, de se relacionar com o mundo.

Piaget preocupou-se em descrever como e em função de que as estruturas mentais sofreriam sucessivas transformações, dando lugar a formas de organização cognitiva cada vez mais complexas no curso do desenvolvimento (Piaget, 1964). Dois conceitos são centrais nesse sentido, a saber, o de adaptação, que pode ser entendido como o uso de mecanismos cognitivos para retornar a um estado de equilíbrio que foi rompido pela ação do mundo físico ou social, e o de equilibração, que descreve o processo da passagem de uma situação de menor equilíbrio para uma de maior equilíbrio. $\mathrm{O}$ desenvolvimento cognitivo, portanto, poderia ser definido como uma "equilibração progressiva, uma passagem contínua de um estado de menor equilíbrio para um estado de equilíbrio superior" (Piaget, 1964, p. 11).

Nessa perspectiva conceitual, a criança é entendida como ativa na relação com o mundo físico e social, iniciadora de ação e movida pela curiosidade intelectual. As transformações cognitivas que ela experimenta são construções que acontecem em função de suas tentativas de entender o mundo ao seu redor, compreender seus eventos e sistematizar suas ideias num todo coerente (Piaget \& Inhelder, 1999). Considerando o papel central dos desequilíbrios para o desenvolvimento, evidencia-se o papel fundamental do ambiente para o desenvolvimento infantil.

Sabe-se que o adoecimento por câncer, ainda hoje, carrega um forte estigma, acompanhado pela ideia da morte (Souza \& Erdmann, 2003), e, nesse contexto, a presença de uma neoplasia na infância é algo difícil e doloroso, tendo em vista que há uma expectativa social de que a infância seja um período de experimentação do mundo, de aprendizagem e de desenvolvimento portanto, de vida. Pode-se inferir que a condição de adoecimento grave nessa fase pode se caracterizar como uma questão contundente. Entretanto, são raras as investigações sobre como a criança, levando em consideração seu processo de desenvolvimento cognitivo, compreende sua condição de hospitalização, adoecimento e tratamento.

Assim, foi objetivo deste estudo caracterizar de que maneira o processo de adoecimento por neoplasia infantil, hospitalização e tratamento são compreendidos pelas crianças, considerando sua etapa de desenvolvimento cognitivo de acordo com a perspectiva piagetiana. A hipótese de trabalho foi que crianças em diferentes estágios de desenvolvimento cognitivo apresentam maneiras diferenciadas de compreender as situações que as cercam, no caso, o adoecimento e a hospitalização, considerando que o pensamento lógico está em processo de desenvolvimento.

Busca-se, dessa forma, investigar como a criança se percebe nesse contexto complexo, o que poderia contribuir para a construção de estratégias de cuidado que levem em conta as necessidades e o ponto de vista dela.

\section{Método}

Participaram do estudo cinco crianças de entre 4 e 9 anos de idade, diagnosticadas com câncer (leucemia), em acompanhamento em um ambulatório especializado em oncologia pediátrica de um hospital da Baixada Santista.

A pesquisa realizada foi qualitativa, visando acessar os processos pelos quais as pessoas envolvidas constroem significados. Essa proposta permitiu entender e interpretar sentidos e significações que os participantes dão aos fenômenos, por meio da observação ampla e entrevistas de profundidade (Turato, 2011). No geral, as pesquisas qualitativas têm um número de participantes relativamente pequeno, variando entre cinco e quinze, e que pode ser modificado para baixo ou para cima de acordo com os objetivos da investigação (Turato, 2011).

Foram utilizados quatro instrumentos: a) diários de campo; b) entrevista semiestruturada com os responsáveis (questionário sociodemográfico e uma entrevista com um roteiro temático com questões sobre a percepção dos pais sobre processos de desenvolvimento da criança, situação atual quanto ao adoecimento, hospitalização e tratamento); c) provas piagetianas de conservação de quantidades discretas, comprimento, líquidos, volume e prova de inclusão de classes; d) técnica projetiva de desenho-estória com tema, na qual se investigou o modo como a criança percebe o contexto de adoeci- 
mento, hospitalização e tratamento, a partir da seguinte consigna: "Faça um desenho e conte uma história sobre o que você sente estando aqui no hospital".

Quanto à análise dos dados, os diários de campo foram analisados levando-se em conta a observação, os registros e os discursos dos participantes, buscando significados relevantes para a compreensão da situação estudada. As entrevistas com os responsáveis foram analisadas de acordo com a Análise de Conteúdo Temática (Bardin, 1988). As provas piagetianas foram avaliadas da maneira prevista no contexto teórico-conceitual (identificando elementos próprios de uma forma de organização cognitiva pré-operatória ou operatória-concreta) e a técnica projetiva de desenho-estória com tema conforme Trinca (Trinca \& Tardivo, 2002).

Para cada criança participante foi construído um kit na forma de uma caixa contendo o material usado para o protocolo, e, ao final de sua aplicação, cada criança ficou com esse material. Em cada kit foram colocados os materiais necessários para a realização das provas piagetianas (contendo círculos de EVA, copos, massa de modelar, cordas e brinquedos) e os procedimentos de desenho (lápis de cor, lápis preto e papel sulfite). A Figura 1 ilustra a caixa e seus componentes.

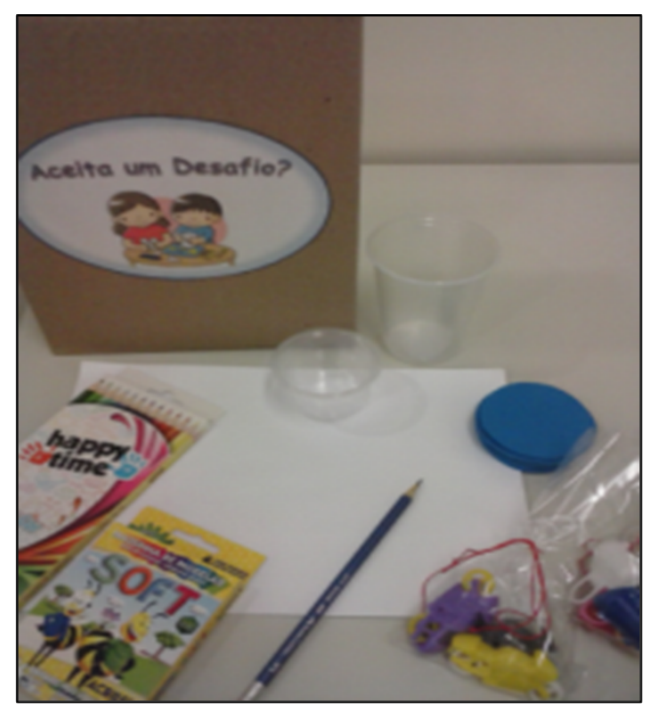

Figura 1

Caixa de materiais para a realização das provas piagetianas e os desenhos-estórias com tema.

O protocolo de pesquisa foi aplicado na brinquedoteca do ambulatório do hospital. Os participantes foram selecionados com a ajuda da equipe de saúde, que forneceu dados para identificação de participan- tes que atendiam aos critérios de inclusão. No dia da consulta, previamente agendada no ambulatório, os responsáveis foram abordados pela pesquisadora e convidados a participar da pesquisa. Os participantes foram esclarecidos sobre o uso e os propósitos das gravações, ficando explícito o uso sigiloso e restrito à pesquisa. Os responsáveis assinaram o Termo de Consentimento Livre Esclarecido (TCLE) e as crianças foram convidadas a participar do trabalho, assinando um Termo de Assentimento Livre e Esclarecido (TALE). Os aspectos éticos deste projeto foram preservados de acordo com a Resolução 466/ 12 do Conselho Nacional de Saúde. O projeto foi aprovado pelo Comitê de Ética da Unifesp sob número CAAE 49559815.2.0000.5505, no parecer de número 1.267.637.

Após a aplicação do TCLE foi realizada a entrevista semiestruturada com os responsáveis e as crianças foram convidadas a participar do trabalho, sendo aplicado o TALE, as provas piagetianas e o procedimento desenho-estória com tema. As entrevistas com os pais foram gravadas em áudio e os protocolos com as crianças foram gravados em vídeo, com expressa autorização dos participantes envolvidos.

\section{Resultados e discussão}

Participaram do estudo cinco crianças e seus responsáveis, sendo três meninos e duas meninas, com idades entre 4 e 9 anos. Quanto ao tipo de câncer, foram convidadas crianças com linfomas ou leucemias sem acometimento metastático neurológico ou alterações de ordem cognitiva ou neurológica que as impedissem de participar do processo de avaliação previsto no protocolo da pesquisa. Todas as crianças responderam ao protocolo de forma completa. Quanto às provas piagetianas, observaram-se duas crianças (com idades de 4 e 6 anos) que se caracterizam como pré-operatórias e três (uma com 8 e duas com 9 anos) como operatórias-concretas.

A seguir, apresentamos como foi a aplicação do protocolo com as crianças, analisando em conjunto a aplicação das provas piagetianas, os desenhos e as observações gerais da criança e da entrevista com o responsável, a fim de promover a articulação de elementos que permitam melhor compreensão dos conceitos envolvidos na análise.

F, sexo feminino, 6 anos de idade, foi diagnosticada com leucemia há pouco mais de um ano e faz tratamento na instituição desde então. Tem sido acompanhada por sua mãe durante as internações e consultas. Mora 
com a avó e com a mãe, que está desempregada desde o diagnóstico. Seus pais são divorciados e F. quase não tem contato com o pai. A mãe mostrou-se disponível para falar, apesar de evidenciar algum desconforto em tratar do adoecimento da filha. Descreve sua filha como uma menina que adora pintar e desenhar, que sempre gostou de ir à escola, mas que, por conta do tratamento, ficou afastada por um longo período. A mãe também observou uma mudança drástica de comportamento da filha após o início do tratamento, apresentando-se mais agitada e com um comportamento difícil, o que estaria exigindo muita paciência e deixando-a exausta.

No contato com a criança, observou-se que não houve dificuldade na aplicação do protocolo, e que ela se mostrava participativa na situação. Das cinco provas realizadas, em quatro (conservação de quantidades discretas, líquidos, volume e prova de inclusão de classes) F respondeu de forma condizente à fase pré-operatória, apesar de ter pensado bastante na resposta da prova de conservação de quantidades discretas, contando várias vezes os círculos e medindo os tamanhos das fileiras. Na prova de conservação de comprimento, a resposta dada por F. foi característica de crianças na fase operatório-concreta. Esses indicativos de transição são esperados ao longo do desenvolvimento e, para efeitos deste estudo, F. será considerada como se organizando cognitivamente de maneira pré-operatória.

Quanto à técnica do desenho-estória com tema, F. começou de forma muito entusiasmada a fazer os primeiros riscos no papel e, a cada risco, narrava seu desenho.

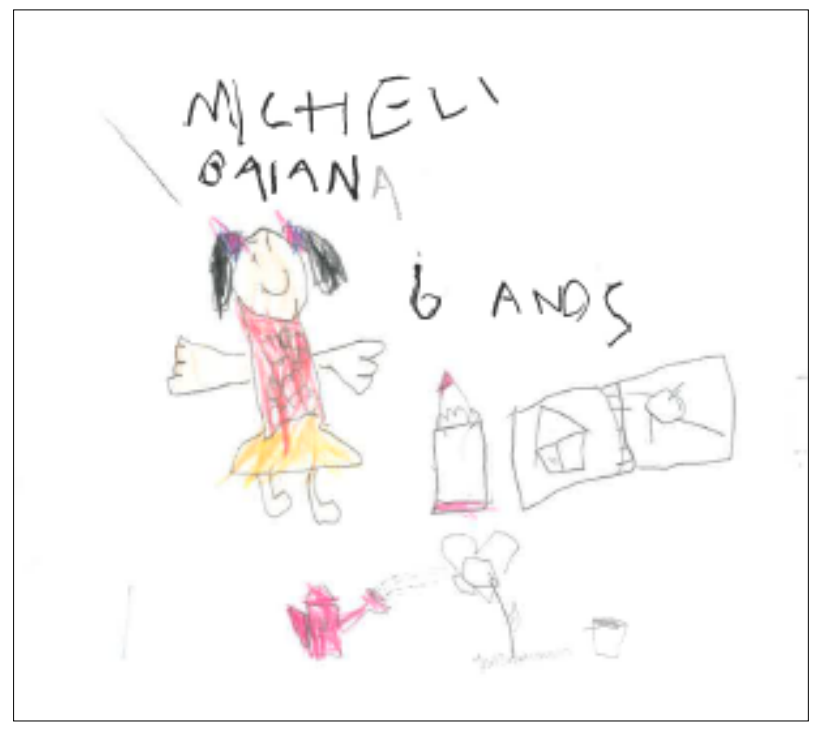

Figura 2

Desenho-estória com tema de F., sexo feminino, 6 anos.
F. começou desenhando uma garota, dizendo que "ela é boa, adora desenhar e pintar, adora flores e seu cabelo é muito bonito". Em seguida, escreveu o nome da menina no topo do desenho ("Micheli Baiana"), junto com a idade. Dizia o quanto essa garota gostava de flores e que flores têm que ser regadas para continuarem vivas. Relatou que a garota do desenho estava pintando na escolinha, ressaltando que fazia tempo que ela não pintava. Em determinado momento, F. pediu para que a pesquisadora escrevesse um recado para a menina do desenho. Pediu que escrevesse "Micheli, adorei te conhecer". Após, a criança disse "eu também gostei muito de te conhecer". A análise do desenho, bem como o discurso produzido pela criança, permite considerar que "Micheli Baiana" é um personagem com o qual ela se identifica. Podemos interpretar esse processo de projeção através do desenho e seu relato como um mecanismo esperado, do ponto de vista psicológico. É relevante destacar, nesse caso, que F. descreveu muitas de suas características anteriores à doença como sendo características da menina desenhada. O cabelo de F está voltando a crescer e o cabelo de Micheli é descrito como lindo e grande, parecendo que a personagem realiza um desejo da criança quanto a algo que lhe falta.

L.G., sexo masculino, 4 anos de idade, foi diagnosticado com leucemia há quatro meses e faz tratamento na instituição desde então. Tem sido acompanhado por sua mãe e por sua avó durante as internações e consultas. Mora com sua mãe, seu padrasto e sua irmã recém-nascida. Contudo, desde o nascimento dela, L.G. mora na casa de sua avó paterna. O contato inicial foi realizado com a mãe, que se mostrou disponível para falar, mas não entrou em detalhes sobre o diagnóstico do filho. Suas respostas foram concisas e os assuntos eram encerrados abruptamente. $\mathrm{O}$ contato com a criança ocorreu em outra data, quando foi acompanhado da avó, que também foi entrevistada e, desta vez, apresentou muitos detalhes, emocionando-se ao contar sobre o início da doença e a demora no diagnóstico. Relata que a mãe da criança parou de acompanhar L.G. após o nascimento de sua filha, de forma que a avó pareceu mais implicada nas questões atuais da criança.

Na aplicação do protocolo com a criança observou-se que ele estava disperso, mas ficou entusiasmado para ver o que tinha na caixa de materiais. Durante a aplicação das provas piagetianas, L.G. participou ativamente das provas de conservação de quantidades discretas, comprimento e líquido, mas após a prova de conservação de volume, em que se utilizava massa de modelar, e a 
de classificação, com o uso de brinquedos, sua atenção ficou mais dispersa. L.G. respondeu a todas as provas de maneira condizente com o período pré-operatório.

Em relação ao procedimento desenho-estória com tema, L.G. fez seu desenho escolhendo as cores e sendo muito sucinto no seu relato. L.G. iniciou uma série de rabiscos e, durante a execução, se expressou dizendo que "o desenho é uma luta". Ele afirma que um lado é bom (aponta para o lado esquerdo do desenho) e o outro lado é mau (lado direito do desenho), dizendo: “Às vezes o vermelho ganha, às vezes é o branco. Mas o branco éo bonzinho, ele vai ganhar sempre! O vermelho vai acabar logo".

A análise do desenho, bem como do discurso produzido pela criança, permite considerar que L.G. faz um desenho que revela algo de sua vivência quanto ao diagnóstico e tratamento oncológico, e que procura construir algum tipo de elaboração simbólica diante disso, com certa noção do que está em questão naquele momento de sua vida: uma batalha entre o lado mau (que parece representar a doença) e o lado bom (que parece representar a cura). De forma espontânea ele relata uma representação metafórica bastante frequente nos discursos de pacientes oncológicos: a vivência do câncer e o tratamento como uma "luta".

Outro ponto interessante é que L.G. parece fazer um prognóstico, com expectativa de bom desfecho, ao afirmar que o lado bom, que pode representar o tratamento, às vezes pode perder, mas no final "o bonzinho vaiganhar sempre". Além disso, ele apresenta uma perspectiva de temporalidade "o vermelho (lado mau) vai acabar logo".

Apesar de podermos nos perguntar a respeito do efeito emocional que o afastamento da mãe estaria gerando para sua experiência atual, mesmo que o escopo deste estudo não permita avançar nesse tipo de análise, aparentemente a avó estaria fazendo o necessário papel de suporte afetivo e prático típico da figura materna.

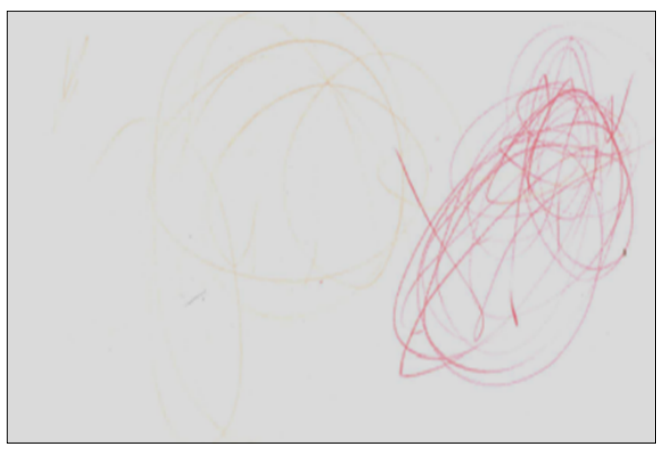

Figura 3

Desenho-estória com tema produzido por L.G., sexo masculino, 4 anos.
G., sexo masculino, 8 anos de idade, foi diagnosticado com leucemia há quase oito anos, com apenas oito meses de idade, e faz tratamento na instituição desde então. Foi acompanhado por sua mãe durante as internações e consultas. Mora com seus pais, sua mãe está desempregada e seu pai é caminhoneiro. Uma das queixas da mãe diz respeito à falta de apoio, visto que ela está, na maior parte do tempo, sozinha. O contato inicial foi realizado com a mãe, e a criança não quis sair de perto dela. Nesse primeiro contato a mãe mostrou-se disponível para falar, muito participativa, contando que, como o diagnóstico fora dado quando ele ainda era um bebê, ela sente a equipe do hospital como parte de sua família, no sentido de pessoas importantes nesse processo.

No contato com a criança, observou-se que ele estava muito tímido e não queria sair de perto de sua mãe, mas ela mesma se afastou. Durante a aplicação das provas piagetianas, G. respondeu a todas as provas de maneira condizente com o período operatório-concreto. Em relação à técnica do desenho-estória com tema, G. pediu para fazer o desenho no verso do TCLE assinado por sua mãe e, após ser questionado sobre o motivo disso, ele insistiu que gostaria de desenhar no mesmo papel em que a mãe assinou, pedindo para assinar atrás do TCLE.

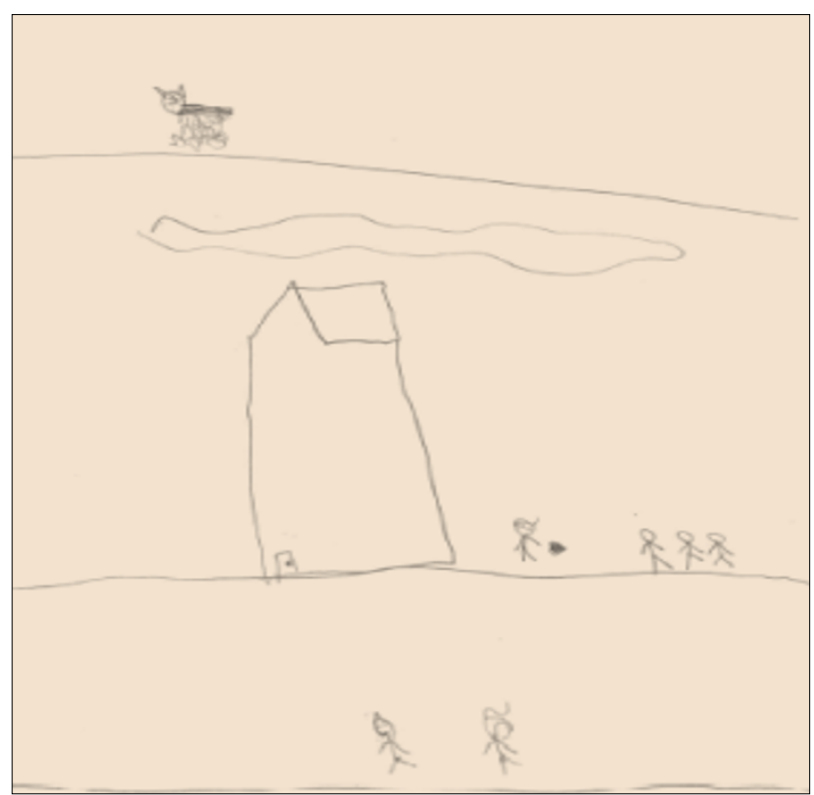

Figura 4

Desenho-estória com tema produzido por G., sexo masculino, 8 anos.

No procedimento de desenho-estória com tema, G. produziu um desenho no qual fala sobre as coisas que gosta de fazer, como jogar futebol com os 
amigos, brincar de correr e ficar com seu cachorro. Comenta que não pode mais fazer tais atividades em função da doença e do tratamento, mas ele diz estar "esperando ficar melhor". A análise do desenho mostra que ele desenha aquilo que lhe faz falta. Podemos interpretar que, do ponto de vista psicológico, G. tem uma representação imaginária que tenta dar conta da elaboração de uma perda. Como podemos observar, G. desenhou na parte de cima da página seu cachorro, no meio da página sua casa e seus amigos do futebol e, por último, o amigo com quem gosta de correr.

N., sexo masculino, 9 anos de idade, foi diagnosticado com leucemia há cinco anos e faz tratamento na instituição desde então. Tem sido acompanhado por sua mãe durante as internações e consultas. Mora com seus pais e duas irmãs mais velhas. Sua mãe está desempregada. O contato inicial foi realizado com sua mãe, que ressaltou a angústia que sentiu com a demora até o diagnóstico e a falta de delicadeza sobre como a notícia foi comunicada para ela e seu marido. N. ficou em tratamento por dois anos e meio, entrou em remissão e, nove meses depois, descobriram que a doença havia voltado. Agora ele está aguardando o transplante de medula.

N. ficou animado por assinar seu primeiro documento (TALE) e quis começar o quanto antes. Com relação às provas piagetianas, respondeu a todas de maneira condizente com o período operatório-concreto. No procedimento desenho-estória com tema, N. diz adorar jogar futebol, mas conta que não pode porque não está forte o suficiente para jogar bem, por conta do tratamento. Ele afirmou que, em função dessa limitação, joga um jogo virtual. Ele desenhou um robô que ele criou no jogo (Figura 5) e disse que "adora este jogo por poder comandar tudo o que acontece em sua vida". Além disso, desenhou seu animal de estimação virtual, também criado por ele, visto que na vida real não pode ter nenhum. Podemos interpretar nesse desenho uma estrutura binária em dois níveis: no primeiro há uma figura humana com um artefato, a bola; no segundo também há uma figura que representa o humano, acompanhado de um "artefato", o animal virtual criado pela criança. Tal estrutura nos faz interpretar que N. parece indicar dois tempos de sua vivência com o câncer. Ele coloca cores no desenho do robô, que parece representar uma "produção atual" da criança diante do adoecimento. Tradicionalmente, o uso de cores representa a expressão do afeto e, nesse caso, pode-se interpretar que a criança tem um foco afetivo (positivo ou negativo) ligado ao momento atual, ou seja, as demandas atuais parecem exigir que a criança disponibilize recursos afetivos mais significativos para lidar com a situação do tratamento. Além disso, a representação da figura do "robô" de um jogo, que lhe permite estar na posição de "comandar", pode indicar uma tentativa de elaboração da angústia na forma de um exercício de retomada simbólica de controle diante de situações a que a criança está atualmente submetida (como restrição de atividades, situação de internação, procedimentos invasivos, entre outros).

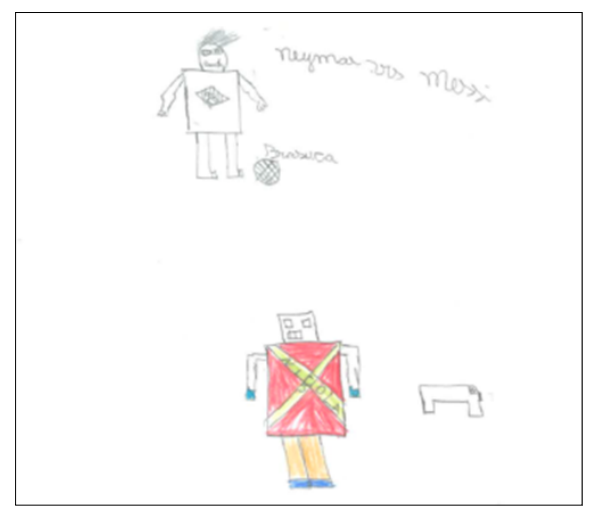

Figura 5

Desenho-estória com tema produzido por N., sexo masculino, 9 anos.

B., sexo feminino, 9 anos de idade, foi diagnosticada com leucemia há pouco mais de seis meses e faz tratamento na instituição desde então. Tem sido acompanhada por sua mãe durante as internações e consultas. Mora com seus pais e sua irmã mais nova, e sua mãe é dona de casa. O contato inicial foi realizado com sua mãe, que estava um pouco relutante no início, mas depois aceitou participar. Ela ressaltou que vê a força da filha no enfrentamento da doença, mas sofre muito desde o diagnóstico, por ter pensamentos constantes de sua filha sofrendo ou indo a óbito. A mãe falou que B. é uma menina alegre, que se relaciona facilmente e positivamente com todas as pessoas.

No contato com a criança observou-se que ela foi receptiva e alegre. Durante a aplicação das provas piagetianas respondeu a todas de maneira condizente com o período operatório-concreto. No procedimento desenho-estória com tema, B. desenhou em duas folhas sua trajetória desde o diagnóstico, numa sucessão de desenhos com um discurso muito elabo- 
rado. Ao final do procedimento desenho-estória ela diz, apontando para uma parte do desenho: "Essa sou eu antes do câncer e essa sou eu depois. O cabelo caiu, mas o sorriso continua porque eu nunca vou perder meu sorriso e minha alegria de viver?".

Ela se representa em vários desenhos sem cabelo, exceto quando desenha seu futuro e seu passado. Durante a execução dos desenhos ela ressalta o que a deixa triste, do que ela sente falta, sua relação com os membros da equipe e seus planos para o futuro. Ela fala da saudade que sente de sua irmã mais nova, retratando várias situações entre elas. Em seu discurso, afirmou que tem medo de deixar seus pais tristes por conta da doença. Outro ponto ressaltado foi sua relação com a equipe do hospital, afirmando: "quero ser enfermeira, eu já conheço tudo aqui no hospital mesmo, quero ajudar as pessoas igual as enfermeiras me ajudam", o que indica uma identificação positiva com os profissionais que a acompanham no tratamento. Podemos ver, a partir de seus desenhos, que essa criança apresentou uma elaborada percepção sobre sua situação, envolvendo elementos de temporalidade (passado-presente-futuro), relações de causalidade, relações de afeto e relações identificatórias. Em seu discurso, observa-se que ela se mostrou intensamente afetada pela perda dos cabelos. Entretanto, afirma que procura encarar essa situação de forma positiva e tenta se mostrar "forte", construindo uma narrativa que busca fazer frente ao sofrimento: mesmo diante de perdas e sofrimento, ela se coloca como alguém capaz de sorrir e que tem alegria de viver. Vemos, então, que os desenhos produzidos por essa criança apresentam conteúdo com maior complexidade, que são contados de maneira lógica, como esperado para uma criança que se organiza cognitivamente de maneira operatória-concreta.

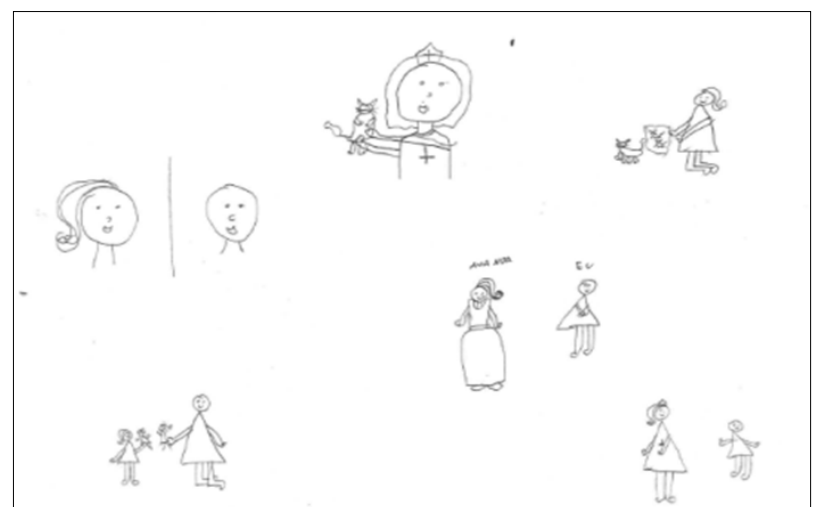

Figura 6

Primeiro desenho-estória com tema produzido por B., sexo feminino, 9 anos.

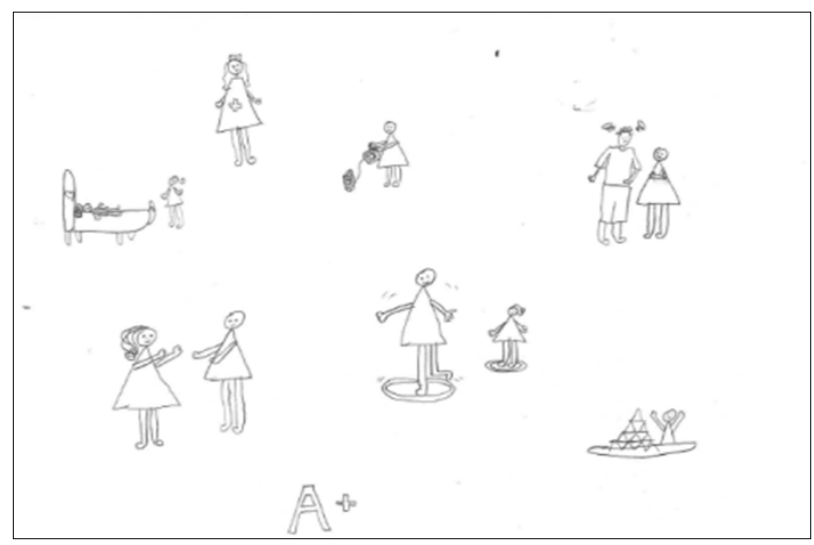

Figura 7

Segundo desenho-estória com tema produzido por B., sexo feminino, 9 anos.

A comparação do desempenho das crianças nas provas piagetianas com as demais avaliações do protocolo (desenho-estória com tema e observação ampla) permite que se avance na análise de outros elementos. O Quadro 1 coloca lado a lado as formas de organização cognitiva das crianças e as significações presentes nos desenhos em cada caso. Observa-se, para todos os cinco participantes da pesquisa, que há coerência entre os dois tipos de avaliação.

\section{Quadro 1}

Quadro comparativo entre a avaliação das provas piagetianas e o desenho-estória com tema.

\begin{tabular}{cccc}
\hline Criança & $\begin{array}{c}\text { Idade } \\
\text { (anos) }\end{array}$ & $\begin{array}{c}\text { Avaliação das provas } \\
\text { piagetianas (Estágios) }\end{array}$ & $\begin{array}{c}\text { Avaliação qualitativa do procedimento desenho-estória } \\
\text { com tema }\end{array}$ \\
\hline F. & 6 & Pré-operatório & $\begin{array}{c}\text { Criou um personagem para falar de si. } \\
\text { L.G. }\end{array}$ \\
4 & Pré-operatório & $\begin{array}{c}\text { Desenhou uma batalha entre cores, simbolizando a luta } \\
\text { contra o câncer. }\end{array}$ \\
\hline
\end{tabular}




\begin{tabular}{cccc}
...continuação & & \\
Criança & $\begin{array}{c}\text { Idade } \\
\text { (anos) }\end{array}$ & $\begin{array}{c}\text { Avaliação das provas } \\
\text { piagetianas (Estágios) }\end{array}$ & $\begin{array}{c}\text { Avaliação qualitativa do procedimento desenho-estória } \\
\text { com tema }\end{array}$ \\
\hline G. & 8 & Operatório-concreto & $\begin{array}{c}\text { Desenho em três níveis. Representou as coisas de que mais } \\
\text { gosta e sente falta. Demonstrou conhecimento dos motivos das } \\
\text { atuais restrições (raciocínio lógico). }\end{array}$ \\
N. & 9 & Operatório-concreto & $\begin{array}{c}\text { Desenhou a si próprio e um personagem criado que lhe } \\
\text { representou. Demonstrou conhecimento dos motivos das } \\
\text { atuais restrições (raciocínio lógico). }\end{array}$ \\
B. & 9 & Operatório-concreto & $\begin{array}{c}\text { Desenho com noções de causa e efeito, justificativas, } \\
\text { explicações sobre a doença, preocupação com pais e planos } \\
\text { futuros. Demonstrou conhecimento dos motivos das atuais } \\
\text { restrições (raciocínio lógico). }\end{array}$ \\
\hline
\end{tabular}

As duas crianças que foram identificadas nas provas piagetianas como estando na fase pré-operatória, durante a elaboração do desenho, se comunicaram por meio de personagens, não se colocaram diretamente nos desenhos e relataram o sofrimento que a doença e a hospitalização trouxeram para suas vidas. Dessa forma, essas crianças expressaram seus sentimentos, seus medos e suas formas de resistir sem que para isso organizassem de forma lógica os elementos ou explicações sobre essa experiência.

Com relação às três crianças que foram avaliadas como estando no período operatório-concreto, podemos notar que elas se colocam muito nos desenhos e nos discursos, falando sobre o que sentem. Particularmente, as três apresentam, de forma muito evidente, tudo aquilo que a doença e a hospitalização impedem que eles façam, gerando sofrimento para cada uma delas. Contudo, elaboram no discurso os motivos pelos quais são privadas de certas coisas. A habilidade de estabelecer relações causais, típica de uma organização cognitiva operatória-concreta, aparece, portanto, produzindo uma nova forma de perceber e compreender a experiência de hospitalização.

As entrevistas semiestruturadas foram realizadas com os responsáveis, sendo todas mulheres, mães ou avó da criança, em um dos casos. Elas foram analisadas em quatro categorias:

a) O lugar do diagnóstico do filho na vida dos responsáveis. Nessa categoria foram explicitadas reações iniciais diante do adoecimento e modos de enfrentamento. As reações mais citadas pelos responsáveis foram incredulidade e medo, algo que também foi identificado por Menezes et al. (2007), que destacaram que, no momento da comunicação do diagnóstico, inicia-se para a família o processo de sofrimento diante da possibilidade de perda do ente querido. Nessa categoria também houve o relato de familiares que se sentiram muito sozinhos e sem apoio, o que nos leva a considerar a importância do suporte emocional para os responsáveis. Duas entrevistadas relataram que sentem que também estão adoecendo enquanto enfrentam o processo de tratamento dos filhos, algo também observado nos trabalhos de Ribeiro e Angelo (2005). Os apelos à religiosidade e à espiritualidade são relatados como fontes de conforto e esperança diante de um momento que consideram desafiador, aspectos que também foram apontados por Araújo et al. (2016). Uma das entrevistadas fala que colocou seu filho "nas mãos de Deus", indicando que há a concepção de que existe um ser espiritual a quem se recorre como meio de suporte para o enfrentamento dos obstáculos. Também houve relatos como "o sofrimento existe para darmos valor à vida”, ressaltando a superação, o aprendizado e a força que esse momento poderia proporcionar, tanto às responsáveis quanto às famílias de modo geral.

b) O olhar do responsável sobre a vivência da criança com câncer. Nessa categoria as responsáveis apresentaram questões como a mudança de comportamento das crianças. Todas as responsáveis relatam que suas crianças demonstram maior necessidade de atenção, seja da própria cuidadora, seja de outras pessoas. Ribeiro e Angelo (2005) comentam que algumas crianças, nesse contexto, passam a ficar o tempo todo junto à mãe e têm dificuldade em separar-se dela, ou, contrariamente, passam a rejeitá-la.

c) Opinião do responsável sobre a equipe de saúde. Nessa categoria foi possível observar a percepção 
que os responsáveis têm da equipe multiprofissional de saúde, reconhecendo ações efetivas de cuidado, como também ressaltando positivamente a influência das voluntárias da instituição e da equipe de apoio do hospital (limpeza, alimentação, entre outros). As responsáveis também relataram que se sentem seguras com as orientações dos médicos. Contudo, enfatizaram que a atitude do profissional, agindo com sensibilidade e delicadeza, influencia diretamente o nível de confiança. De acordo com Araújo (2004), é crucial que os responsáveis conheçam sobre a doença, pois, com isso, os sentimentos de insegurança tendem a ser minimizados, além de ser preciso esclarecer suas dúvidas e ideias pré-concebidas, o que reforça a importância de uma boa comunicação entre os envolvidos.

d) Opinião sobre a pesquisa. Alguns entrevistados ressaltaram que a pesquisa também é uma forma de contribuir para que outros familiares possam enfrentar esse momento difícil do adoecimento de um filho.

\section{Considerações finais}

Todas as crianças participantes mostraram compreensão de sua situação de adoecimento e tratamento, apresentando diferentes formas de enfrentamento. Além disso, todas ressaltaram uma posição otimista em relação às perspectivas de cura, independentemente do momento do desenvolvimento cognitivo. A compa- ração entre o desempenho nas provas piagetianas e nos outros elementos do protocolo (desenho-estória com tema e observação) mostrou que todos os participantes apresentaram coerência entre os tipos de avaliação, indicando que a forma de se organizar cognitivamente tem implicações importantes na maneira de a criança perceber, compreender e experimentar a vivência da hospitalização e tratamento em oncologia.

Um tema recorrente entre as crianças foi o das restrições e perdas diante do tratamento, como o afastamento dos amigos e da escola, a saudade da família e as restrições a certas brincadeiras. O efeito da perda dos cabelos também chama a atenção, pois todas as crianças abordaram essa questão em algum momento, durante a produção dos desenhos, das histórias ou nas conversas informais. Em relação às entrevistas com os responsáveis, destaca-se a importância do suporte ao cuidador, que lida com inúmeros desafios e mudanças.

Este trabalho procurou caracterizar como os processos de hospitalização, adoecimento e tratamento são compreendidos pelas crianças. Nesse sentido, foram explorados os significados atribuídos pelas crianças a essas experiências e analisadas as relações entre esses significados e a forma como a criança se organiza cognitivamente. Espera-se, assim, contribuir com as investigações na área de hospitalização infantil e desenvolvimento, bem como fornecer subsídios que possam sustentar práticas de cuidado no contexto hospitalar e que contemplem um olhar para os sujeitos e suas necessidades singulares.

\section{Referências}

Anders, J. C., \& Souza, A. I. J. (2009). Crianças e adolescentes sobreviventes ao câncer: Desafios e possibilidades. Ciência Cuidado e Saúde, 8(1), 131-137. https://doi.org/10.4025/cienccuidsaude.v8i1.7788

Araújo, A. D., Silva, L. G., Delmondes, G. A., Santiago, I. C. L., Kerntopf, M. R., \& Albuquerque, G. A. (2016). Cuidador de criança com câncer: Religiosidade e espiritualidade como mecanismos de enfrentamento. Revista Cuidarte, 7(2), 1318-1324. https://doi.org/10.15649/cuidarte.v7i2.336

Araújo, T. C. C. F. (2004). Câncer infantil: Intervenção, formação e pesquisa em psico-oncologia pediátrica. Psicologia Hospitalar, 4(1), 1-12.

Bardin, L. (1988). Análise de conteúdo. Edições 70.

Bradding, A., \& Horstman, M. (1999). Using the write and draw technique with children. European Journal of Oncology Nursing, 3(3), 170-175. https://doi.org/10.1016/S1462-3889(99)80801-1

Instituto Nacional de Câncer. (2014). Estimativa 2014: Incidência de câncer no Brasil. https://www.inca.gov.br/ bvscontrolecancer/publicacoes/Estimativa_2014.pdf

Menezes, C. N. B, Passareli, P. M., Drude, F. S., Santos, M. A., \& Valle, E. R. M. (2007). Câncer infantil: Organização familiar e doença. Revista Mal-Estar e Subjetividade, 7(1), 191-210.

Piaget J. (1964). Seis estudos de psicologia (24a ed.). Forense Universitária.

Piaget, J. (1970). A construção do Real na Criança. Zahar. 
Piaget, J. (1975). A formação do símbolo na criança. Zahar.

Piaget J., \& Inhelder, B. (1999). A psicologia da criança. Bertrand Brasil.

Ribeiro, C. A., \& Angelo, M. (2005). O significado da hospitalização para a criança pré-escolar: Um modelo teórico. Revista Escola de Enfermagem, 39(4), 391-400. https://doi.org/10.1590/S0080-62342005000400004

Souza, A. I. J., \& Erdmann, A. L. (2008). A criança com diagnóstico de câncer: Revisitando o caminho das políticas de atendimento. Revista Gaúcha de Enfermagem, 24(1), 23-33.

Trinca, W., \& Tardivo, L. (2002). Desenvolvimentos do procedimento de desenhos-estórias (D-E). In J. A. Cunha et al., Psicodiagnóstico-V(pp. 428-438). Artmed.

Turato, E. R. (2011). Tratado de metodologia da pesquisa clínico-qualitativa. Vozes.

Utkan, M. S. (2012). Children hospital design in children picture. Procedia:Socialand Behavioral Sciences, 51, 110-114. https://doi.org/10.1016/j.sbspro.2012.08.127

\section{Luiza Garutti Alvarenga Fonseca}

Psicóloga pela Universidade Federal de São Paulo (Unifesp), Santos - SP. Brasil.

E-mail: luiza.garutti@hotmail.com

(1) https://orcid.org/0000-0002-9543-0972

Sara Del Prete Panciera

Professora Associada do Departamento de Saúde, Educação e Sociedade da Universidade Federal de São Paulo (Unifesp), Santos - SP. Brasil.

E-mail: sara.panciera@unifesp.br

(1) https:// orcid.org/0000-0001-9979-0644

\section{Karina Franco Zihlmann}

Professora Associada do Departamento de Saúde, Educação e Sociedade da Universidade Federal de São Paulo (Unifesp), Santos - SP. Brasil.

E-mail: karina.zihlmann@unifesp.br

(1) https://orcid.org/0000-0001-9822-7518

Endereço para correspondência:

Universidade Federal de São Paulo. Campus Baixada Santista. Rua Silva Jardim, 136, Vila Mathias. CEP: 11015-020. Santos - SP. Brasil.

Recebido 17/12/2017

Aceito 25/06/2018

Received $12 / 17 / 2017$

Approved 06/25/2018

Recibido 17/12/2017

Aceptado 25/06/2018 
Fonseca, L. G. A., Panciera, S. D. P., \& Zihlmann, K. F. (2021). Hospitalização em Oncologia Pediátrica na Teoria de Piaget.

Como citar: Fonseca, L. G. A., Panciera, S. D. P., \& Zihlmann, K. F. (2021). Hospitalização em oncologia pediátrica e desenvolvimento infantil: Interfaces entre aspectos cognitivos e afetivos. Psicologia: Ciência e Profissão,

41 (n.spe 3), 1-13. https:// doi.org/10.1590/1982-3703003189238

How to cite: Fonseca, L. G. A., Panciera, S. D. P., \& Zihlmann, K. F. (2021). Hospitalization in pediatric oncology and child development: Cognitive and affective interface. Psicologia: Ciência e Profissão, 41 (n.spe 3), 1-13. https://doi. org/10.1590/1982-3703003189238

Cómo citar: Fonseca, L. G. A., Panciera, S. D. P., \& Zihlmann, K. F. (2021). Hospitalización en oncología pediátrica y desarrollo infantil: Interfaces entre aspectos cognitivos y afectivos. Psicologia: Ciência e Profissão, 41 (n.spe 3), 1-13. https://doi.org/10.1590/1982-3703003189238 
No artigo "Hospitalização em Oncologia Pediátrica e Desenvolvimento Infantil: Interfaces entre Aspectos Cognitivos e Afetivos", com número de DOI: https://doi.org/10.1590/ 1982-3703003189238, publicado na Revista Psicologia: Ciência e Profissão, 41, e189238:

Onde se lia: "Sara Del Prete Pancieira"

Leia-se:

"Sara Del Prete Panciera” 